\title{
1 Secondary invasion: the bane of weed management
}

2

3 Dean E. Pearson ${ }^{\mathrm{a}, \mathrm{b}}$, Yvette K. Ortega ${ }^{\mathrm{a}}$, Justin B. Runyon ${ }^{\mathrm{c}}$, Jack L. Butler ${ }^{\mathrm{d}}$

4

6

7

9

10

11

12 ABSTRACT

13 Exotic plant invasions present a global threat to natural ecosystems, yet the efficacy of

14

15 is that of secondary invasion - an increase in abundance of non-target exotics following

16

17 analysis directed at quantifying the magnitude of secondary invasion effects and identifying

18 possible causes. Of 168 studies examining the efficacy of exotic plant management in terrestrial

19 habitats, 29\% quantified community responses sufficiently to evaluate secondary invasion.

20 Meta-analysis of 60 cases from 38 studies showed that control efforts strongly reduced target

21 invader abundance overall, but secondary invaders increased, with a mean effect size that was

22 double that found for native plants, which increased only weakly. Moreover, $89 \%$ of the 
23 secondary invaders identified were classified as noxious or invasive plants. Increases in

24 secondary invaders were correlated with target invader reductions, but control method and target

25 invader growth form failed to explain variation in secondary invader responses. These results

26 suggest that target invader suppression is the key factor driving release of secondary invaders.

27 However, management side effects, target invader legacy effects, provenance effects, and

28 shifting environmental conditions may all facilitate secondary invasion. Invasive plant

29 management often successfully suppresses target invaders, but the result is largely secondary

30 invasion. Addressing this problem requires management strategies that anticipate and suppress

31 secondary invaders while rapidly restoring native plants to fill the space vacated by the target

32 weed. Accomplishing the latter will require improved re-vegetation techniques.

34 Key words:

35 Invasive plant, Invasion treadmill, Noxious weed, Restoration, Revegetation, Reseeding 36

\section{1. Introduction}

Exotic plant invasions disrupt ecosystem services and cost the global economy billions of dollars annually (Mack et al., 2000; Pimentel et al., 2005; Sinden et al., 2005). A substantial portion of these costs arise from management efforts directed at suppressing invader abundance

41 (Binns et al., 2001; Pimentel et al., 2005; Sinden et al., 2005). While it is important to control

42 invasive plants and promote native biodiversity, overall efficacy of such management efforts is 43 not clear. Ultimately, the intent of invasive plant control efforts in natural areas is not only to 
44 suppress target invaders but also to mitigate their impacts and promote community recovery

45 (Denslow and D’Antonio, 2005; Hulme 2006; Zavaleta et al., 2001). However, reviews of

46 natural areas invasive plant management indicate that many studies evaluating control efforts do

47 not quantify community-level response to control efforts, leaving us blind to the overall

48 outcomes of management (Denslow and D'Antonio, 2005; Kettenring and Adams, 2011; Reid et

49 al., 2009). This lack of community-level focus has been attributed to the fact that pest

50 management originates from less complex agricultural ecosystems where reductions in pest

51 abundance are linked more directly to proportional increases in desirable crop species (Pearson

52 and Ortega, 2009). However, invasive plant management in natural ecosystems involves much

53 greater complexity, and reducing pest abundance may not always directly translate to ecosystem

54 recovery.

Numerous factors can inhibit ecosystem recovery following suppression of a dominant

56 invader in natural areas. First, limited precision of management tools can result in direct

57 negative effects of the tool itself on desirable ecosystem components (Dickens et al., 2015;

58 Mason and French, 2007; Pearson and Ortega, 2009). For example, using broadleaf herbicides to

59 control invasive forbs can suppress native forbs (Crone et al., 2009; Ortega and Pearson, 2011;

60 Pokorney et al., 2010; Rinella et al., 2009). Second, ecosystem recovery may be deterred by

61 legacy effects that persist following invader suppression, such as when an invader has altered

62 soil properties, disturbance regimes, or reduced native propagule sources (D'Antonio and

63 Vitousek, 1992; Magnoli et al., 2013; Seabloom et al., 2003). Third, provenance effects may

64 favor invader over native recovery due to introduction filters that select for disturbance-adapted 
65 traits or release from natural enemies (Buckley and Catford, 2016; Liu and Stiling, 2006).

66 Finally, shifting environmental conditions such as those driven by anthropogenic changes may

67 favor exotics over natives in ways that impede native recovery (Bauer and Reynolds, 2015;

68 MacDougall and Turkington, 2005). An additional obstacle to ecosystem recovery, potentially

69 interrelated with those described above, is secondary invasion - the proliferation of non-target

70 invaders following efforts to suppress dominant target invaders (Kettenring and Adams, 2011;

71 Butler and Wacker, 2010; Ortega and Pearson, 2009; Larson and Larson, 2010; Symstad, 2004).

72 For example, large-scale suppression of spotted knapweed (Centuarea stoebe) across critical

73 wildlife foraging areas of the Rocky Mountains resulted in substantial increases in the secondary

74 exotic, cheatgrass (Bromus tectorum; Ortega and Pearson, 2010, 2011), the only invader in this

75 ecosystem having greater impact on native plants than spotted knapweed (Pearson et al., 2016).

76 Given that most ecosystems contain multiple species of invaders (Kuebbing et al., 2013), the

77 threat of secondary invasion is a potentially ubiquitous problem requiring immediate attention.

78 Recent reviews of the invasive plant management literature suggest that secondary

79 invasion may be widespread. Kettenring and Adams (2011) conducted a global review

80 addressing a broad range of invasive plant management questions and noted that $>25 \%$ of the

81 studies reviewed found control efforts to promote invasion of secondary exotics. Reid et al.

82 (2009) reviewed the scientific literature and conducted manager surveys to evaluate outcomes of

83 invasive plant control efforts in Australia and reported that $>50 \%$ of studies evaluating

84 community responses to management demonstrated increases in non-target exotic plant species.

85 Abella (2014) reported similar results for invasive plant control treatments conducted on United 
86 States National Park Service lands, finding increases in non-target exotics in $44 \%$ of studies

87 despite lower prevalence of exotics in these protected ecosystems. Increasingly, studies that

88 focus on quantifying community responses to invasive plant management are calling attention to

89 secondary invasion (Dickens et al., 2015; Magnoli et al., 2013; Ortega and Pearson, 2011;

90 Ruwanza et al., 2013; Saito and Tsuyuzaki, 2012; Skurski et al., 2013). Collectively, the

91 evidence suggests that secondary invasion may present a significant barrier to restoration of

92 natural areas threatened by invasive plants, yet we still know little about when and why it occurs.

93 Herein, we present results from a global review and meta-analysis of the invasive plant

94 management literature directed at quantifying the extent of the secondary invasion problem and

95 exploring its potential causes within terrestrial ecosystems. Our main objectives were to 1)

96 quantify the overall effect of invasive plant control measures on secondary invader abundance, 2)

97 determine whether the management approach employed, the type of invader targeted, or the type

98 of secondary invader influenced the degree of secondary invasion, 3) evaluate how the response

99 of the target invader and native plant community to management correlated with the degree of

100 secondary invasion, and 4) offer guidelines for mitigating secondary invasion to promote the

101 conservation of natural areas threatened by exotic plant invasions.

102

103 2. Materials and methods

1042.1 Literature review

105 We searched Google Scholar (http://scholar.google.com) and ISI Web of Knowledge

106 (http://apps.webofknowledge.com) to generate a database of publications assessing effects of 
107 invasive plant control treatments in terrestrial ecosystems as of October 2014, with no restriction 108 on publication date. We used the following search terms: ("invasive plant" or "exotic plant" or 109 "non-native plant" or "nonnative plant" or "introduced plant" or "weed") AND ("control" or 110 "biological" or "prescribed fire" or "herbicide" or "mechanical" or "remov*"). Articles were 111 included in the database if they met the following basic criteria: 1) quantitatively examined 112 invasive plant control treatments in natural, terrestrial ecosystems (no agriculture, greenhouse, or 113 laboratory settings; no aquatic habitats), 2) targeted exotic plant invaders, and 3) were peer-

114 reviewed. If multiple papers reported on the same research, we included only the most 115 comprehensive paper (see evaluation criteria below). We also screened the references of 116 included articles for other relevant publications. Each study meeting these basic criteria was 117 then reviewed in detail to assess to what extent they met specific methodological criteria deemed 118 sufficient to evaluate secondary invasion. These criteria were: 1) the effect on the target invader 119 was quantified using a valid population-level metric (cover, biomass, density, or frequency), 2) 120 the effect on at least one non-target invader was quantified using a valid population-level metric, 121 and 3) the study design included a valid untreated control from which to evaluate treatment 122 effects. For each study included, we also recorded descriptive information including the identity 123 and growth form of the target species, the treatment method, the study region, and the ecosystem 124 type. We used $X^{2}$ tests for homogeneity of variance to examine whether the proportion of studies 125 with one or more methodological issues (failing to meet above criteria) varied among time 126 periods defined by publication year or among the three most common invasive plant treatment 
127 methods, and whether the proportion of studies with each of the three methodological issues

128 differed among the three most common treatment methods.

1292.2 Meta-analysis

130 To quantify the overall response of secondary invaders to control efforts and relate this to

131 the response of target invaders and native taxa, we conducted a meta-analysis using standard

132 methodologies (Koricheva and Gurevitch, 2014; Osenberg et al., 1999; Rosenberg et al., 2000).

133 This technique offers important advantages over 'vote-counting methods' which simply tally the

134 proportion of studies with significant results. Not only do meta-analyses estimate the magnitude

135 of effects, they also account for study quality, override statistical idiosyncracies of constituent

136 papers, and have greater statistical power for detection of effects (Gurevitch and Hedges, 1999;

137 Rosenberg et al., 2000; Stewart, 2010).

138 Our meta-analysis was restricted to the subset of studies from our review that 1)

139 quantified abundance (cover, biomass, density, or frequency) of at least one non-target exotic, 2)

140 had a valid control/treatment design (see criteria above), and 3) reported associated mean values.

141 For each study, we obtained mean values and measures of variation (SD or SE) and sample size

142 for each valid case comparing treated and control groups (see treatment categorization below).

143 Data for up to three response variables were extracted directly from tables or from figures using

144 Web Plot Digitizer software (http://arohatgi.info/WebPlotDigitizer/app). To represent the

145 response of secondary invaders to treatment, we extracted abundance data for non-target exotic

146 plants. If data were presented for multiple groups or species of non-target exotic plants, we used

147 the species with the greatest increase in response to treatment, since secondary invasion by one 
148 species is sufficient to preclude successful management. We also extracted abundance data 149 representing the response of target invaders, and in the $8 \%$ of studies that presented data 150 separately for multiple target species or groups, we selected the invader most suppressed by 151 treatment. Finally, we extracted abundance data representing the response of natives as a group. 152 If data were presented separately by functional group, we summed the means and associated 153 variances. For the $16 \%$ of studies that reported more than one abundance metric for each response 155 variable, we used only one metric to avoid interdependence issues (Gurevitch and Hedges, 156 2001), prioritizing according to how commonly the metrics were used across all studies as 157 follows: cover $>$ biomass $>$ density $>$ frequency. We included versions of these metrics that 158 represented relative values, e.g., the proportion of the total cover represented by the response 159 group. Where possible, we chose the same abundance metric to represent all response variables 160 from a given study. Many studies reported data on the effects of multiple invasive plant 161 treatments. In such cases, we extracted one mean per treatment type. We categorized treatments 162 as follows: 'removal' - relatively selective treatments including biological control (one case 163 only), pulling, cutting, and discrete applications of herbicide to only the target species;

164 'herbicide' - herbicide application across all plant taxa in treatment plots; 'herbicide mix'- plot165 scale herbicide application (as above) in combination with another treatment method (usually fire 166 but also mechanical or seeding treatments); 'mechanical'- mowing, raking, and/or disking; and 167 'other' treatment methods including fire $(n=6)$ grazing $(n=2)$ and seeding $(n=1)$ that were applied 168 across treatment plots. For the $11 \%$ of studies that manipulated background ecological factors 
169 that did not represent invasive plant control treatments per se (e.g., nutrient levels, livestock 170 access), we only considered results from non-manipulated plots.

171 Many studies included multiple versions of a given treatment type, for example, varying

172 the type of herbicide, and/or the application rate or timing. For each treatment category defined

173 above, we extracted data for the one version that was most effective at suppressing the target, as

174 this is the common metric of invasive plant control success. In the few cases where the

175 suppressive effect was equal among multiple treatment types, we then chose the one with bigger

176 secondary response. If results were presented over multiple years, we used only the final year of

177 data. If results were presented separately for different sites or regions, we chose the location

178 with the highest baseline level of target invaders, as measured in control plots. If levels of target

179 invaders were comparable among sites or regions or went unreported, we used data for the 180 location with the highest baseline level of secondary invaders (i.e., in control plots). We opted

181 not to pool data across locations given that results were sometimes variable in terms of the 182 degree of target suppression effected and/or the degree of the secondary response, such that 183 averaging responses across locations would have diluted patterns.

184 We used MetaWin v2.1 software to calculate effect sizes and conduct all meta-analyses 185 (Rosenberg et al., 2000). We chose Hedges $d$ as our effect size metric for all response variables, 186 calculated for each treatment type, or case, per study. Hedges $d$ is a unit free index that 187 standardizes the difference in mean abundance between treated and control groups by accounting 188 for variance and also corrects for any bias introduced by small sample sizes (Rosenberg et al., 189 2000). The largest effect sizes are derived from cases showing large differences in response 
190 between treated and control plots and low variability among plots. Zero $d$ values signify no

191 difference in the response between treated and control plots, while positive and negative $d$ values

192 imply a general trend for an increase and decrease, respectively. For the $8 \%$ of studies included

193 in our meta-analysis that did not report variance metrics necessary for calculation of $d$, we used

194 the method of Wolf and Guevara (2001) to estimate variance based on that reported in other

195 relevant studies. Specifically, for each response variable and abundance metric, we doubled the

196 largest reported standard deviation and assigned this value to all missing standard deviation data.

197 This conservative procedure ensured that all cases reporting valid means were utilized while

198 ensuring that estimated values were down-weighted in the meta-analysis. To summarize effects

199 for each response variable, we calculated the weighted mean effect size $\left(d_{+}\right)$across relevant

200 cases. To test whether mean values of $d_{+}$differed significantly from zero (i.e., indicating

201 significant effects), we assessed whether the 95\% bootstrap-confidence interval (CI) of $d_{+}$

202 overlapped zero based on 999 iterations (Rosenberg et al., 2000). We also tested whether effects

203 sizes across all cases were homogeneous using the $Q_{t}$ statistic which represents total

204 heterogeneity. A significant $Q_{t}$ based on a $X^{2}$ test indicates that the variance among effect sizes

205 is greater than that expected by sampling error alone (i.e., effect sizes are not equal across

206 studies).

207 We used two types of mixed meta-analysis models to examine potential sources of

208 heterogeneity among effect sizes. In all cases, we considered fixed factors of interest with the

209 inclusion of an error term to account for random variation in effect sizes among studies

210 (Rosenberg et al. 2000). Inspection of effect sizes plotted against the normal quantiles for each 
211 response variable revealed no deviation from normality (Rosenberg et al., 2000). Hence we used 212 the parametric version of statistics testing for significance of fixed factors. Categorical models 213 were used to compare effect sizes among types of 1) treatments, 2) target invaders, and 3)

214 secondary invaders. Invader types were categorized by growth form as forbs, grasses, or woody 215 species consisting of trees and shrubs. For analysis of secondary invader type, studies lumping 216 non-target invaders across growth forms were excluded. We note that each study represented the 217 response of a single secondary invader type given that we only included the species or group 218 with the largest treatment response in our meta-analysis (even though multiple species or groups 219 may have responded). To test whether mean effect sizes differed among categorical factors, we 220 assessed the significance of the between-group heterogeneity statistic $\left(Q_{b}\right)$ based on the $X^{2}$ 221 distribution. To test for potential interactions among categorical factors, we conducted tests in a 222 hierarchical fashion so that the effect of one factor was tested within each level of another factor 223 (Koricheva and Gurevitch, 2014). Sample sizes limited the testing of all possible interactions, 224 but we were able to consider those interactions that made the most ecological sense.

225 Specifically, after testing each of the three factors separately for differences among categories, 226 we isolated each target invader group and repeated the tests for differences by treatment type and 227 secondary invader type, respectively. Categories with at least two cases were included in 228 comparisons. We also explored variation in effect sizes by life cycle (annual or biennial vs 229 perennial) of target and secondary invaders, but do not report results given that no patterns were 230 apparent and sample sizes were small when examining interactions with other factors of interest. 
To relate treatment effects among secondary invaders, target invaders, and natives, we

232 used continuous models employing weighted least-squares regression (Rosenberg et al., 2000).

These meta-regression models allowed us to test whether variation in effect sizes of one response variable correlated with effect sizes of a second response variable. We assessed the significance of the relationship, or slope term, using the model heterogeneity statistic $\left(Q_{m}\right)$, as evaluated with the $X^{2}$ distribution. We calculated $r^{2}$ values for this term by dividing $Q_{m}$ by $Q_{t}$ (Myers and Harms 2009). To assess whether the effect size for the focal response variable differed from 0 when the effect size of the second response variable was 0 , we also assessed the significance of the intercept term based on the Z-score and a normal distribution. For the secondary invader effect, we screened for potential variation in the target invader effect by treatment type, target type and secondary invader type, respectively, by running separate models for each category except where sample sizes were limited $(n<10$ for mechanical and other treatments, woody targets, woody secondary invaders). Slope estimates were comparable in magnitude and direction among testable categories, hence we present results only for overall tests conducted across categories. Due to sample size constraints, we could not examine whether the relationship between native effect sizes and other response groups varied among categories of interest.

We included data for multiple treatment types per study in meta-analyses to enable us to more comprehensively test for variation in effects by treatment type and other potential moderator variables. To assure that our conclusions were not sensitive to pseudoreplication, we re-ran our overall analysis that tested for significance of each response variable with the inclusion of only a single randomly selected effect size per study. The mean effect size for each 
252 response variable was similar to that obtained when all cases were included and the CIs

253 overlapped between the reduced dataset and the whole dataset. As a consequence, we felt

254 confident in including all the data in our analyses.

255 To aid in interpretation of our results, we tested for temporal changes in effect sizes,

256 potentially indicative of publication bias or changes in methodology, management approaches,

257 etc. (see Koricheva and Gurevitch, 2014). We found no evidence for temporal changes in effect

258 sizes when we tested for variation by publication year for the secondary invader effect $\left(r^{2}=0.001\right.$,

$259 Q_{m}=0.11, P=0.7, n=60 ;$ slope=0.007, $\left.\mathrm{SE}=0.18,\right)$, target invader effect $\left(r^{2}=0.002, Q_{m}=0.01\right.$,

$260 P=0.89, n=54 ;$ slope $=0.004, \mathrm{SE}=0.03)$, or native effect $\left(r^{2}=0.03, Q_{m}=0.96, P=0.33, n=31\right.$;

261 slope $=0.03, \mathrm{SE}=0.03$ ). Additionally, we estimated the fail-safe number, or the number of studies

262 that would have to be added to change the results of the meta-analysis for the secondary invader

263 response (Rosenberg et al., 2000). This number was 1301, indicating that the observed results

264 can be treated as a reliable estimate of the true effect based on the criteria presented in

265 Rosenberg (2005). As further indication that our results were robust to publication bias (i.e.,

266 differential publication of studies showing significant effects, potentially biasing against studies

267 with smaller sample sizes; Rosenberg et al., 2000), effect sizes were not correlated with sample

268 size (Spearman's rank $r=0.03, P=0.79$ ). Finally, we checked our meta-analysis against the

269 quality criteria established by Koricheva and Gurevitch (2014) for ecological studies.

\section{3. Results}

$272 \quad 3.1$ Literature review 
We compiled 168 studies satisfying basic criteria for inclusion in our review (Appendix

274 A). These studies targeted 108 exotic plant species for control, of which $36 \%$ were shrubs or

275 trees, $33 \%$ forbs, $23 \%$ grasses, and $7 \%$ vines. The most common targets were the perennial forbs

276 Centaurea stoebe ( $n=13$ studies) and Euphorbia esula $(n=13)$, the annual forb Centaurea

277 solstitialis $(n=8)$, the annual grass Taeniatherum caput-medusae $(n=9)$, and the shrubs Tamarix

$278 \operatorname{spp}(n=5)$. In $86 \%$ of the 168 studies, a single species was the focus of control efforts. Studies

279 used a variety of treatment methods, with 53\% including multiple methods. Invasive plant

280 treatments most commonly involved herbicide $(n=95)$, mechanical means $(n=78)$, and/or

281 biological control $(n=36)$. Most studies (80\%) were conducted in North America, with the

282 remainder conducted in Australia/New Zealand (8\%), Africa (5\%), Europe (3\%), South America

$283(3 \%)$, and Asia (1\%). Nearly half of studies (48\%) were conducted in grasslands and prairies

284 (including rangelands and abandoned agriculture with representative native vegetation), followed

285 by forest/woodland (22\%), riparian (12\%), coastal dunes/scrub (8\%), shrubland (7\%), desert

$286(3 \%)$, and alpine ecosystems $(<1 \%)$.

287

Of the 168 studies included in our review, 71\% $(n=119)$ had methodological limitations

288 precluding evaluation of secondary invasion. Notably, the proportion of studies failing to meet

289 criteria for evaluation of secondary invasion declined significantly in the most recent publication

290 years assessed $\left(X^{2}=6.7, \mathrm{df}=2, P=0.03\right)$, as $56 \%$ of 41 studies published from $2010-2013 \mathrm{had}$

291 methodological issues compared to $79 \%$ of 72 studies published from $2006-2009$ and $70 \%$ of 54

292 studies published 1959-2005 (Fig. 1). The proportion of studies with methodological issues also

293 varied significantly across the three most common treatment methods $\left(X^{2}=15.9, \mathrm{df}=2, P=0.003\right)$. 
294 Studies with methodological issues included $97 \%$ of 36 biological control studies in contrast to $29562 \%$ of 78 studies employing mechanical methods and $66 \%$ of 69 herbicide studies. The most 296 common methodological issue, associated with $56 \%(n=94)$ of studies, was failure to quantify 297 effects on secondary exotics using a valid abundance metric (cover, biomass, density, or 298 frequency). About a third $(n=33)$ of these studies focused solely on the target species and did not 299 measure the response of any other community components, whether secondary exotics or 300 natives. The remaining two thirds of studies $(n=62)$ did measure at least one community 301 component, yet did not distinguish abundance of secondary exotics. Most commonly, secondary 302 exotics were lumped with natives $(n=34)$ or went completely unmeasured $(n=17)$. Other 303 problems included lumping of secondary exotics with target exotics $(n=6)$, and measurement of 304 species richness but not abundance of invaders, again with target and secondary exotics lumped $305(n=4)$. Nearly a third $(n=29)$ of the 94 papers with limitations in their examination of secondary 306 effects had additional methodological issues explained below.

307 The second most common methodological issue was study design, attributed to $24 \%$ ( $n$ $308=41)$ of studies. Studies with design issues had no control group and simply followed trends in 309 treated plots over time $(n=27)$, used uninvaded rather than invaded plots as controls $(n=11)$, or 310 had no true replication to represent the control and/or treatment group $(n=2)$. Almost half $(n$ $311=19$ ) of the 41 studies with design limitations had other methodological issues. The final 312 methodological issue we identified, associated with $11 \%(n=19)$ of studies, was failure to 313 quantify target invader effects using a valid abundance metric. These studies either limited 
314 assessment of target invader effects to individual level performances measures or did not include

315 any metrics of target control. All but one of these 19 studies had other methodological issues.

316 The proportion of studies with each of the three methodological issues varied among

317 treatment types $\left(X^{2}=12.1, \mathrm{df}=4, P=0.017\right)$. For studies involving herbicide and mechanical

318 control, far more studies had limitations in quantification of secondary invaders ( $73 \%$ and $59 \%$,

319 respectively) versus study design (15\% and 30\%, respectively). In contrast, a similar proportion

320 of biological control studies had limitations in quantification of secondary invaders and study

321 design (47\% vs 43\%). For all three treatment types, target invader effects were ill-quantified in

322 about $10 \%$ of studies.

323

$324 \quad 3.2$ Meta-Analysis

325 Of 168 papers meeting criteria for review, $38(23 \%)$ met criteria for meta-analysis, which

326 included adequate quantification of secondary invader abundance, valid study design, and

327 presentation of mean values for treatment and control groups. This subset of studies targeted 33

328 species, and in $84 \%$ of cases, focused on a single species. Nearly $50 \%(n=18)$ of the 38 studies

329 included in meta-analysis presented data for multiple treatment types, with $78 \%$ of multi-

330 treatment studies including two treatment types and the remainder three types. The set of 38

331 studies yielded 60 cases for which we calculated effect sizes comparing mean abundance in

332 treated and control plots for up to three response groups: target invaders, secondary invaders, and

333 native species, respectively. 
Invasive plant control treatments significantly reduced abundance of target invaders (Fig. 335 2a), with a negative effect size in $94 \%$ of 52 cases. Effect sizes for target invaders exhibited 336 significant variability among cases $\left(Q_{t}=93.03, \mathrm{df}=51, P=0.0003\right)$. Furthermore, mean effect 337 sizes differed significantly among the five treatment types tested $\left(Q_{b}=9.32, \mathrm{df}=4, P=0.05\right)$.

338 Although all treatment types significantly suppressed target invader abundance, mean effect sizes 339 were about twice as large for removal, herbicide, and herbicide mix treatments as compared to 340 mechanical and other treatments (Fig. 2a). However, effects of treatment on target invader 341 abundance did not differ significantly among types of target invaders, as categorized by growth 342 form $\left(Q_{b}=2.75, \mathrm{df}=2, P=0.25\right.$; Table 1$)$. We also found no evidence for an interaction between 343 target invader type and treatment type. Although effects on target invader abundance did not 344 differ significantly among treatment types when target grasses $\left(Q_{b}=5.47, \mathrm{df}=4, P=0.24\right)$ and 345 target forbs $\left(Q_{b}=5.2, \mathrm{df}=3, P=0.16\right)$ were tested separately, mean effect sizes for treatment types 346 followed the same pattern seen when all target invaders were tested together, with removal, 347 herbicide, and herbicide mix treatments trending towards greater suppression as compared to 348 mechanical and other treatments (Table B1). Variation by treatment type could not be assessed 349 for woody targets due to sample size limitations ( $n=3$ of 4 cases employed removal methods). Invasive plant control treatments significantly increased abundance of secondary invaders 351 (Fig. 2b), with positive effect sizes in $75 \%$ of 60 cases. Effect sizes exhibited significant 352 variability among cases $\left(Q_{t}=91.58, \mathrm{df}=59, P=0.004\right)$. However, mean effect sizes did not differ 353 significantly among the five treatment types tested $\left(Q_{b}=3.75, \mathrm{df}=4, P=0.44\right.$; Fig. $\left.2 b\right)$. Similarly, 354 effects of treatments on secondary invader abundance did not differ significantly among types of 
355 target invaders $\left(Q_{b}=0.7, \mathrm{df}=2, P=0.71\right.$; Table 1$)$. We also did not find evidence for an interactive 356 influence of target invader type and treatment type on the response of secondary invaders in that

357 effect sizes did not differ significantly among treatment types when target grasses $\left(Q_{b}=3.51\right.$, $358 \mathrm{df}=4, P=0.48)$ and target forbs $\left(Q_{b}=0.42, \mathrm{df}=3, P=0.94\right)$ were tested separately (Table B2).

359 Woody targets were not tested given that this group had little variation in the treatment type 360 employed ( $n=8$ of 11 cases used removal methods).

Of the cases for which we had information on the growth form of the secondary invaders

362 included in our meta-analysis, 54 documented the response of grasses or forbs to treatments and 363 only 1 documented the response of woody taxa. Hence, only the first two groups of secondary 364 invaders could be compared. When all types of target invaders were included in the analysis, 365 there was no significant difference in the response of secondary invaders that were grasses $366\left(d_{+}=0.5, \mathrm{CI}=0.12\right.$ to $\left.0.88, n=25\right)$ vs forbs $\left(d_{+}=0.54, \mathrm{CI}=0.29\right.$ to $0.83, n=29 ; Q_{b}=0.03, \mathrm{df}=1$, $367 P=0.86)$. However, when target groups were considered separately, effects differed between 368 secondary grasses and forbs, indicative of an interaction between the type of target invader and 369 secondary invader. When grasses were the target of control efforts, secondary forb invaders had 370 a stronger response than secondary grasses $\left(Q_{b}=8.0, \mathrm{df}=1, P=0.005\right)$, with forbs increasing 371 significantly $\left(d_{+}=0.82, \mathrm{CI}=0.55\right.$ to $\left.1.07, n=9\right)$ but grasses not $\left(d_{+}=0.03, \mathrm{CI}=-0.34\right.$ to $\left.0.44, n=7\right)$. 372 Conversely, when forbs were the target invaders, secondary grasses trended towards a stronger 373 response than secondary forbs $\left(Q_{b}=2.61, \mathrm{df}=1, P=0.1\right)$, with grasses increasing significantly $374\left(d_{+}=0.87, \mathrm{CI}=0.41\right.$ to $\left.1.33, n=15\right)$ but forbs not $\left(d_{+}=0.37, \mathrm{CI}=-0.12\right.$ to $\left.0.86, n=13\right)$. For woody 375 target invaders, there was no significant difference between the response of secondary grasses 
$376\left(d_{+}=-0.83, \mathrm{CI}=-2.59\right.$ to $\left.1.31, n=3\right)$ and forbs $\left(d_{+}=0.46, \mathrm{CI}=0.05\right.$ to $0.9, n=7 ; Q_{b}=2.51, \mathrm{df}=1$,

$377 P=0.11$ ), although sample sizes were limited.

378 Invasive plant control treatments significantly increased abundance of native plants, with

379 a positive effect size in $61 \%$ of 31 cases, although the mean effect size was small, with a

380 confidence interval that nearly crossed 0 (Fig. 2c). Effect sizes for native abundance did not

381 exhibit significant variability among cases $\left(Q_{t}=34.35, \mathrm{df}=30, P=0.27\right)$, nor did mean effect sizes

382 differ significantly among treatment types $\left(Q_{b}=3.15, \mathrm{df}=4, P=0.53\right.$; Fig. 2$)$ or among types of

383 target invaders $\left(Q_{b}=2.42, \mathrm{df}=2, P=0.3\right.$; Table 1$)$.

384

385

3.2.1 Relationships among response variables

Across the 52 case studies with relevant data, the magnitude of the secondary invader

387 effect increased significantly with the degree of target invader suppression effected by treatments

388 (Fig. 3a; $Q_{m}=20.7, \mathrm{df}=1, P<0.0001, r^{2}=0.27$; slope= -0.24, $\mathrm{SE}=0.05$ ). Notably, the secondary

389 effect did not deviate significantly from 0 when the target effect was 0 (intercept $=-0.11$,

$390 \mathrm{SE}=0.13, P=0.41)$. These relationships were robust to removal of one extreme point $\left(Q_{m}=13.84\right.$,

$391 \mathrm{df}=1, P=0.0002, r^{2}=0.2 ;$ slope $=-0.23, \mathrm{SE}=0.06 ;$ intercept $\left.=0.16, \mathrm{SE}=0.13, P=0.24\right) . \quad$ In contrast,

392 the degree of the secondary invasion was positively associated with the response of natives

393 across 31 cases with relevant data (Fig. $3 b ; Q_{m}=5.01, \mathrm{df}=1, P=0.025, r^{2}=0.09$; slope $=0.43$,

$394 \mathrm{SE}=0.19$ ), with a significant secondary effect even when the native effect was 0 (intercept $=0.61$,

$395 \mathrm{SE}=0.15, P=0.0007)$. However, when one extreme point was removed, the relationship between

396 the response of secondary exotics and natives was no longer significant $\left(Q_{m}=1.45, \mathrm{df}=1, P=0.23\right.$, 
$397 r^{2}=0.03 ;$ slope $\left.=0.25, \mathrm{SE}=0.21\right)$, with the secondary effect remaining significant in the absence of 398 a native effect (intercept $=0.63, \mathrm{SE}=0.15, P=0.0003$ ). As seen with secondary exotics, treatment 399 effects on native plant abundance increased with increased suppression of target invaders (Fig. $4003 \mathrm{c} ; Q_{m}=8.81, \mathrm{df}=1, P=0.003, r^{2}=0.22 ;$ slope=-0.18, $\left.\mathrm{SE}=0.06\right)$, and the native effect did not 401 deviate significantly from 0 when the target effect was 0 (intercept $=-0.19, \mathrm{SE}=0.17, P=0.24)$. 402 However, the relationship between native and target responses weakened substantially when we 403 removed an extreme value $\left(Q_{m}=2.39, \mathrm{df}=1, P=0.12, r^{2}=0.07 ;\right.$ slope $\left.=-.12, \mathrm{SE}=0.08\right)$, and the 404 native effect still did not deviate significantly from 0 in the absence of a target effect (intercept= $405-0.08, \mathrm{SE}=0.18, P=0.67)$.

406

407 4. Discussion

Our literature review and meta-analysis indicate that secondary invasion presents a

409 formidable barrier to the conservation of natural areas threatened by invasive plants. While our 410 meta-analysis demonstrated strong reductions in the abundance of targeted invaders across 411 studies, the general response across management approaches was a substantial increase in non412 target exotic plants - secondary invaders - that corresponded with a weak increase in native 413 plants. The mean effect size for secondary invaders was more than double that for natives, 414 which was small in magnitude and bordered non-significance. Moreover, 89\% of the secondary 415 invaders pose significant risks to native ecosystems as indicated by their inclusion on noxious 416 weed and invasive plant lists (Table B3). Collectively, these community-level outcomes suggest 417 that invasive plant management efforts are not currently achieving significant conservation gains. 
418 To advance conservation of natural areas that are increasingly threatened by exotic plant

419 invasions around the globe, we need to better understand and address the problem of secondary

420 invasion.

421 So why does secondary invasion occur? Our meta-analysis supports the idea that

422 secondary invaders respond to conditions of decreased competition and increased resource

423 availability resulting from suppression of targeted invaders (Buckley et al., 2007; D'Antonio and

424 Meyerson, 2002; Kettenring and Adams, 2011). Our analysis demonstrated that increases in

425 secondary invader abundance correlated significantly with reductions in target invader

426 abundance, a relationship documented in a few prior case studies (Erskine Ogden and Rejmanek,

427 2005; Ortega and Pearson, 2010; Symstad, 2004). We also found that management efforts did

428 not significantly affect the abundance of secondary invaders when they failed to suppress the

429 target invaders, suggesting that management tools did not generate substantial side effects

430 independent of target invader control. All the management approaches that we evaluated

431 effected target suppression and elicited secondary invasion, with more successful target

432 suppression generally related to greater increases in secondary invaders. Indeed, while the

433 average effect size for the increase in secondary invaders was moderate in magnitude across all

434 studies $\left(d_{+}=0.57, \mathrm{CI}=0.36\right.$ to $\left.0.8, n=60\right)$, the effect was large $\left(d_{+}=0.83, \mathrm{CI}=0.56\right.$ to $\left.1.11, n=36\right)$

435 when less suppressive treatments were excluded from studies testing multiple control methods.

436 In theory, controlling the target invader should allow ecosystem recovery (e.g., Smith and van

437 den Bosch 1967), yet our results indicated that target invader suppression instead led to 
438 secondary invasion. So the question of why secondary invasion occurs is really a question of 439 why exotics benefit more than natives following the control of a dominant invader.

An obvious prerequisite for secondary invasion is the presence of other exotic plants to

441 exploit the space vacated by the target invader. Multiple invaders are becoming the norm in

442 many terrestrial plant communities (Kuebbing et al., 2013; Pearson et al., 2016), thereby setting

443 the stage for widespread secondary invasions. In ecosystems with multiple invaders, negative

444 interactions among invaders are common, suggesting an important role of invader-invader

445 competition (Kuebbing and Nuñez, 2015). Hence, the suppression of a dominant invader might

446 be expected to release subordinate exotic competitors. However, native competitors should also

447 be released. Likewise exotics are adept at exploiting disturbances (Davis et al., 2000), but both

448 natives and secondary exotics should have access to the resources released via general treatment-

449 related disturbances. So increased resource availability alone does not explain why exotics win

450 out over natives following target invader control. Provenance could be sufficient to explain why

451 exotics benefit more than natives following control efforts if the introduction process strongly

452 favors exotic organisms that bear "weedy" traits or escape from natural enemies (Buckley and

453 Catford, 2016; Pearson et al., 2014; Liu and Stiling, 2006; Ricciardi and Rasmussen 1998; Keane

454 and Crawley, 2002). However, additional factors that might help explain why exotics benefit

455 more from target invader control include: treatment side effects, legacy effects of the target

456 invader, and environmental shifts.

457 Analogous to treatments applied in human medicine, all invasive plant management 458 actions have potential side effects (Pearson and Ortega, 2009). Side effects include unintended 
459 impacts on non-target ecosystem components such as soil compaction, direct damage to native 460 plants, and indirect suppression of natives via altered food chains (Dickens et al., 2015; Mason

461 and French, 2007; Rinella et al., 2009; Zavaleta et al., 2001). In short, invasive plant control is

462 not simply precision removal of the target invader. Rather management actions represent a form

463 of disturbance with positive and negative direct and indirect effects of varying strength on the

464 target invader, non-target natives and exotics, and abiotic ecosystem components (Buckley et al., 465 2007; D’Antonio and Meyerson, 2002; Hobbs, 2007; Pearson and Ortega, 2009; Zavaleta et al., 466 2001). Understanding management outcomes and the extent to which they may favor secondary 467 invaders over natives requires understanding how all of these dynamics play out.

468 We anticipated that more selective management strategies, those designed to affect only 469 the target invader, would be less likely to facilitate secondary invaders by minimizing side 470 effects. However, this expectation was not well supported across studies. For example, host 471 specific biological control agents represent perhaps the most precise invasive plant management 472 tool. While too few biocontrol studies met criteria for inclusion in our meta-analyses as an 473 explicit category, numerous biocontrol studies documenting declines in target invaders have 474 reported strong increases in secondary invaders (Butler and Wacker, 2010; Larson and Larson, 475 2010; Denslow and D’Antonio, 2005; Lesica and Hanna, 2004; Huffaker and Kennett, 1959). 476 Similarly, in our meta-analysis, the most selective control method we evaluated, 'removal' 477 (biological control, hand pulling, cutting, and/or specific application of herbicide to only the 478 target invader), elicited strong increases in secondary invaders, whereas less selective methods 479 tended towards smaller effects. Overall, target invader suppression appeared more important 
480 than precision of the management tool in driving secondary responses. This finding suggests

481 that the size of the 'hole' left by target invader suppression is the most important factor

482 determining secondary invader responses. Nonetheless, specific case studies show that side

483 effects of management can themselves promote secondary invasion independent of target invader

484 control (Firn et al., 2010; Olson and Wallander, 1998; Ortega and Pearson, 2010).

485 Due to treatment side effects, the specific control technique employed can play an

486 important role in determining which taxa may be released following suppression of the target

487 invader. Both non-target exotics and natives are susceptible to suppressive effects of treatment,

488 but those that escape direct harm may take advantage of the new conditions created by control

489 efforts. The reciprocal invader responses we observed, wherein control of a target forb was

490 followed by greater increases in exotic grasses, or the opposite, illustrate how management tools

491 may shift the balance among exotic (and/or native) functional groups within the community. In

492 the most obvious example, many herbicides used to control invasive plants have limited

493 selectivity in that they broadly suppress either monocots or dicots, leaving the non-susceptible

494 group unharmed. Hence, use of a broadleaf herbicide to suppress a target invasive forb can also

495 suppress non-target forbs, both native and exotic, while fueling the release of grasses (Skurski et

496 al., 2013; Ortega and Pearson, 2010, 2011; Erskine Ogden and Rejmanek, 2005). Accordingly,

497 if the prospective secondary invaders include grasses, then this management tool can trigger

498 secondary invasion, a scenario depicted in many studies we reviewed (Sheley et al., 2006;

499 Laufenberg et al., 2005; Symstad, 2004; Tyser et al., 1998; and references above); but if the

500 prospective secondary invaders are forbs alone, a much less common scenario, the same 
501 treatment can impede secondary invasion (Goodall et al., 2010). While more selective tools like 502 biological control focus suppression on the target invader, the resultant hole still allows for 503 secondary invasion of those non-target exotics present if other measures are not deployed to 504 counter their response. Increasing precision of management tools is critical to managing for 505 increased plant biodiversity following invasion, but it will not resolve the secondary invasion 506 problem.

507 Legacy effects arise when invaders alter conditions in ways that persist after the invader 508 is gone (Cuddington, 2012). A few invasive plant control studies indicate that legacy effects on 509 soil properties persisting after invader control can favor exotic over native recovery (Symstad, 510 2004; Yelenik et al., 2004). In the context of the novel weapons hypothesis (Callaway and 511 Aschehough, 2000), certain secondary exotics might be expected to benefit over natives in the 512 presence of target invader legacies if the exotics share evolutionary history. Alternatively, given 513 that such legacy effects by definition represent novel conditions within the community, 514 secondary invaders might benefit over natives because they represent a broader range of traits. It 515 is unclear how often legacy effects might promote secondary invasion, many exotics alter 516 conditions in ways that can generate legacy effects (D'Antonio and Meyerson, 2002; D'Antonio 517 and Vitousek, 1992; Jordan et al., 2008; Magnoli et al., 2013; Symstad, 2004; Yelenik et al., 518 2004). Invaders may also generate legacy effects by simply reducing native propagule sources 519 via suppression of native plants over long time periods and broad spatial scales, a condition that 520 can be addressed by reseeding native pants (Seabloom et al., 2003). Legacy effects that persist 521 following invader control are likely an important factor contributing to secondary invasion. 
Anthropogenic activities are rapidly changing our natural world via eutrophication,

523 global climate change, altered disturbance regimes, etc. (Galloway et al., 2008; Schwartz et al.,

524 2006; Vitousek et al., 1997). These shifts can benefit exotics over natives with the result that

525 invaders may act as passengers rather than drivers of community change (MacDougall and

526 Turkington, 2005). Such shifting environmental conditions could also help to explain why

527 secondary invasion is such a common response to invasive plant control efforts (Hobbs, 2007;

528 Firn et al., 2010). Recognizing when invaders are drivers versus passengers of community

529 change is important, because when invaders are passengers the driving factors need to be

530 managed to effect the desired long-term outcome, at least whenever this is possible.

Previous reviews of invasive plant management efforts have used vote-counting methods

532 to highlight the problem of secondary invasion (Abella et al., 2014; Kettenring and Adams,

533 2011; Reid et al., 2009), but there have been no rigorous analyses examining the factors

534 potentially influencing secondary invasion. Our meta-analysis is the first to quantify secondary

535 invasion and relate its variability directly to suppression of the target invader. Nonetheless, there

536 are a number of caveats to consider. Foremost is the fact that only a small proportion of studies

537 actually quantified management outcomes sufficiently to evaluate secondary invasion, leaving us

538 with limited sample sizes for addressing more complex questions. Furthermore, studies were

539 skewed towards North America, reflecting the bias in research efforts directed at invasive species

540 (Pysek et al., 2008; Kettenring et al. 2011). We also note several factors affecting the estimation

541 of secondary invader effect sizes in our meta-analysis. Studies included in our meta-analysis

542 sometimes did not report the response of non-target exotics likely to be released by efforts to 
543 control target invaders, instead reporting data only for non-target exotics susceptible to treatment

544 (e.g., Pokorny et al., 2010; Rinella et al., 2009; but see Skurski et al., 2013). Similarly, many

545 studies reported the response of only a single non-target exotic (e.g., Aigner and Woerley, 2011;

546 Firn et al., 2010; Sher et al., 2008; Symstad, 2004). As a result, we were forced to pick a single

547 species or group to represent the response of secondary invaders even in the many studies where

548 multiple species or groups increased following treatment. Accordingly, the effect size for the

549 secondary response often represented only a subset of the exotic taxa released via control efforts

550 (e.g., Enloe et al., 2005; Ruwanza et al., 2013; Saito and Tsuyuzaki, 2012; Wilson et al., 2008).

551 Alternatively, in many other cases, studies presented data for non-target exotics as a single

552 group, and hence, the effect size represented the net response across all constituent taxa (e.g.,

553 Andrue et al., 2010; Butler and Wacker, 2010; Hendrickson and Lund, 2010; Loh and Daehler,

554 2008). Despite this variability, meta-analysis revealed an overarching pattern wherein at least

555 some component of the non-target exotic community tended to increase markedly due to

556 treatment. Such an increase in any one exotic taxon may have large negative ramifications for

557 the community, particularly when the secondary invaders are recognized invasive pests, as we

558 found to be common (Table B3). In contrast, the native effect in our meta-analysis summarized

559 the net response across constituent taxa in all cases, reflecting the nature of data reporting and

560 that natives are generally desirable as a group.

561 Finally, we note that the magnitude of effect sizes estimated in our meta-analysis was

562 likely affected by the limited post-treatment time window examined in most studies (median=2

563 years, range 1-16 years). Secondary invader populations may build for years following treatment 
564 (e.g., Loh and Daehler, 2008; Ortega and Pearson, 2010, 2011; Skurski et al., 2013), but may

565 also wain following factors such as re-invasion of the target invader or recovery of the native

566 community. To address the longevity of secondary effects, future studies must evaluate

567 responses over longer time spans, particularly beyond the typically restricted window of target

568 invader suppression (e.g., Rinella et al., 2009). While spatial scale can also affect conclusions if

569 research is conducted at small scales if management is conducted at larger scales, we found that

570 the majority of studies included in our meta-analysis applied treatments at broad scales $(57 \%$ of

571 studies had treatment plots of at least $100 \mathrm{~m}^{2}$ ). Meta-analysis offered no evidence that the

572 magnitude of the secondary effect varied between studies conducted at broad versus smaller

573 scales (plot size $\leq 30 \mathrm{~m}^{2} ; Q_{b}=0.53, \mathrm{df}=1, P=0.47, n=58$ ).

574 Given the prevalence of secondary invasions, how can we avoid this problem? While

575 there is a clear need to advance research efforts to better understand secondary invasion in the

576 future, interim guidelines based on the best current information are needed to help mitigate this

577 problem towards restoration of weed-invaded ecosystems. Accordingly, we offer a simple

578 dichotomous guide to management actions for reducing secondary invasion (Fig. 4). Future

579 management must begin by evaluating communities for the presence of other exotics that may

580 emerge as important secondary pests. In single invader ecosystems, weed management can

581 focus on the target invader. However, these ecosystems are increasingly rare, and as the prospect

582 for problematic secondary invaders increases, management strategies must become more

583 sophisticated and complex, involving contingencies for suppressing prospective problematic

584 secondary invaders (e.g., Firn et al., 2010). In all management scenarios, if the target species is 
585 known to have legacy effects that may inhibit natives or favor problematic exotics, efforts should

586 be made to mitigate these effects as part of the treatment (e.g., Magnoli et al., 2013).

587 Minimizing the size of the disturbance generated by management efforts in both space and time

588 can help to reduce the opportunity for secondary invasion, e.g., by spot spraying in lieu of

589 broadcasting herbicides and by targeting earlier stages of invasion (Ortega and Pearson, 2010,

590 2011; Pearson and Ortega, 2009; Pokorny et al., 2010; Skurski et al., 2013). In situations when

591 the likelihood of promoting problematic secondary invaders is high and mitigation strategies for

592 such invaders are lacking, the no action management alternative may be advisable.

593 Given that the hole created by suppression of the target invader appears to be a primary

594 factor linked to secondary invasion, revegetation is a critical complementary tool for inhibiting

595 secondary invasion and reinvasion by the target species to achieve overall restoration and

596 biodiversity goals (Cutting and Hough-Goldstein, 2013). However, at present, revegetation

597 efforts appear largely inadequate to address this problem (Kettenring and Adams, 2011). Of

598 those studies meeting our criteria for evaluation of secondary invasion, only six tested for effects

599 of seeding on the response of secondary invaders, with two of these studies reporting successful

600 mitigation of secondary invasion (Enloe et al., 2005; Sheley et al., 2006) and four studies

601 reporting no effect (Endress et al., 2008; Pokorny et al., 2010; Stanley et al., 2011b; Tyser et al.,

602 1998). One obvious impediment is that reseeding efforts too commonly fail to effectively recruit

603 seeded species (e.g., Hulet et al., 2010; Firn et al., 2010; Symstad, 2004; Wilson et al., 2008).

604 New developments in reseeding technology offer promise in this regard (e.g., Madsen et al.,

605 2012, 2014), but broad advances in revegetation technology are needed to take the next step in 
natural areas restoration (Bauer and Reynolds, 2015; Dickens et al., 2015). Succession and resilience theory both provide important frameworks that should be better integrated into weed management (Meiners et al., 2015; Chambers et al., 2014; Sheley et al., 2006; Luken, 1990).

\section{Conclusion}

Secondary invasion has arisen as the bane of weed management. Generally, the more successful the suppression of target invaders, the greater is the response of undesirable secondary invaders. This problem must be overcome to advance conservation and restoration of the many natural areas threatened by exotic plant invasions around the globe. Our review and metaanalysis highlights future research needed to address this problem. First, we found that few studies that examined invasive plant control in natural areas actually quantified exotic species responses within the community sufficiently to assess secondary invasion. Future research must go beyond quantifying the target invader's response to also evaluate how natives and secondary invaders respond to management actions. Beyond this, there is a need for research to elucidate the mechanisms favoring exotics over natives following management actions. Our findings suggest that four primary factors may facilitate secondary invasion and should be further explored: treatment side effects, target invader legacy effects, provenance effects, and shifting environmental conditions. If it turns out that the primary explanation for secondary invasion is that natural ecosystems are changing in ways that favor exotic species over natives, then natural areas conservation may need to consider less traditional approaches going forward (Hobbs et al. 2006; Hobbs 2007). However, refining weed control tools to reduce side effects, neutralize 
627 invader legacies, and mitigate provenance advantages in conjunction with advancing restoration

628 tools to fill the gap resulting from invader suppression, will go far towards improving invasive 629 plant management and natural areas restoration.

630

631 Acknowledgements

632 We thank Peter Lesica and Bryce Christiaens for helpful comments on the manuscript.

633 Jennifer Birdsall conducted the literature review, and Hilary Schultz help with manuscript

634 preparation. This work was funded by the USDA FS, Rocky Mountain Research Station.

635 
641

642

643

644 645

646

647

648

649

650

651

652

653

654

655

656

References

Abella, S.R., 2014. Effectiveness of exotic plant treatments on National Park Service lands in the United States. Invasive Plant Sci. Manag. 7 (1), 147-163.

Aigner, P.A., Woerly, R.J., 2011. Herbicides and mowing to control barb goatgrass (Aegilops triuncialis) and restore native plants in serpentine grasslands. Invasive Plant Sci. Manag. $4(4), 448-457$.

Andreu, J., Vilà, M., 2010. Risk analysis of potential invasive plants in Spain. J. Nat. Conserv. $18(1), 34-44$.

Bauer, J.T., Reynolds, H.L., 2015. In press. Restoring native understory to a woodland invaded by Euonymus fortunei: multiple factors affect success. Restor. Ecol. 00, 00-00.

Binns, J.A., Illgner, P.M., Nel, E.L., 2001. Water shortage, deforestation and development: South Africa's Working for Water programme. Land Degrad. Dev. 12 (4), 341-355.

Buckley, Y.M., Bolker, B.M., Rees, M., 2007. Disturbance, invasion and re-invasion: managing the weed-shaped hole in disturbed ecosystems. Ecol. Lett. 10 (9), 809-817.

Buckley, YM., Catford, J., 2016. Does the biogeographic origin of species matter? Ecological effects of native and non-native species and the use of origin to guide management. J. Ecol., 104(1), 4-17.

Butler, J.L., Wacker, S.D., 2010. Lack of native vegetation recovery following biological control of leafy spurge. Rangeland Ecol. Manage. 63 (5), 553-563.

Callaway, R.M., Aschehoug, E.T., 2000. Invasive plants versus their new and old neighbors: a mechanism for exotic invasion. Science. 290 (5491), 521-523. 
657 Cardinale, B.J., Srivastava, D.S., Duffy, J.E., Wright, J.P., Downing, A.L., Sankaran, M., 658 Jouseau, C., 2006. Effects of biodiversity on the functioning of trophic groups and ecosystems. Nature. 443 (7114), 989-992.

660 Chambers, J.C., Miller, R.F., Board, D.I., Pyke, D.A., Roundy, B.A., Grace, J.B., Schupp, E.W., 661 Tausch, R.J., 2014. Resilience and resistance of sagebrush ecosystems: implications for state and transition models and management treatments. Range. Ecol. Manage. 67, 440-

663 454.

664 Crone, E.E., Marler, M., Pearson, D.E., 2009. Non-target effects of broadleaf herbicide on a 665 native perennial forb: a demographic framework for assessing and minimizing impacts. J.

666 Appl. Ecol. 46 (3), 673-682.

667 Cuddington, K., 2011. Legacy effects: the persistent impact of ecological interactions. Biol. 668 Theory. $6(3), 203-210$.

669 Cutting, K.J., Hough-Goldstein, J., 2013. Integration of biological control and native seeding to 670 restore invaded plant communities. Restor. Ecol. 21 (5), 648-655.

671 Davis, M.A., Grime, J.P., Thompson, K., 2000. Fluctuating resources in plant communities: a 672 general theory of invasibility. J. Ecol., 88 (3), 528-534.

673 D'Antonio, C., Meyerson, L.A., 2002. Exotic plant species as problems and solutions in 674 ecological restoration: a synthesis. Restor. Ecol. 10 (4), 703-713.

675 D'Antonio, C.M., Vitousek, P.M., 1992. Biological invasions by exotic grasses, the grass/fire 676 cycle, and global change. Ann. Rev. Ecol. Syst. 23, 63-87. 
677 Denslow, J.S., D’Antonio, C.M., 2005. After biocontrol: assessing indirect effects of insect $678 \quad$ releases. Biol. Control. 35 (3), 307-318.

679 Dickens, S.M., Mangla, S., Preston, K.L., Suding, K.N., 2015. In press. Embracing variability: 680 environmental dependence and plant community context in ecological restoration. Restor. 681 Ecol. 00, 00-00.

682 Endress, B.A., Parks, C.G., Naylor, B.J., Radosevich, S.R., 2008. Herbicide and native grass 683 684 685 686 687 688 689 690 691 692 693 694 695 seeding effects on sulfur cinquefoil (Potentilla recta)-infested grasslands. Invasive Plant Sci. Mange. 1 (1), 50-58.

Enloe, S.F., DiTomaso, J.M., Orloff, S.B., Drake, D.J., 2005. Perennial Grass Establishment Integrated with Clopyralid Treatment for Yellow Starthistle Management on Annual Range. Weed. Technol. 19 (1), 94-101.

Firn, J., House, A.P., Buckley, Y.M., 2010. Alternative states models provide an effective framework for invasive species control and restoration of native communities. J. Appl. Ecol. 47 (1), 96-105.

Goodall, J., Braack, M., De Klerk, J., Keen, C., 2010. Study on the early effects of several weedcontrol methods on Parthenium hysterophorus L. Afr. J. Range Forage Sci. 27 (2), 95-99.

Galloway, J.N., Townsend, A.R., Erisman, J.W., Bekunda, M., Cai, Z., Freney, J.R., Martinelli, L.A., Seitzinger, S.P., Sutton, M.A., 2008. Transformation of the nitrogen cycle: recent trends, questions, and potential solutions. Science. 320 (5878), 889-892.

696 Gurevitch, J., Hedges, L.V., 1999. Statistical issues in ecological meta-analyses. Ecology. 80 (4), 697 1142-1149. 
Gurevitch, J., Hedges, L.V., 2001. Meta-analysis: combining the results of independent experiments. Oxford University Press, New York.

Hendrickson, J.R., Lund, C., 2010. Plant community and target species affect responses to restoration strategies. Rangeland Ecol. Manage. 63 (4), 435-442.

Hobbs, R.J., Arico, S., Aronson, J., Baron, J.S., Bridgewater, P., Cramer, V.A., Epstein, P.R., Ewel, J.J., Klink, C.A., Lugo, A.E., Norton, D., Ojima, D., Richardson, D.M., Sanderson, E.W., Valladares, F., Vila, M., Zamora, R., Zobel, M., 2006. Novel ecosystems: theoretical and management aspects of the new ecological world order. Glob. Ecol. Biogeogr. 15 (1), 1-7.

Hobbs, R.J., 2007. Setting effective and realistic restoration goals: key directions for research. Restor. Ecol. 15 (2), 354-357.

Huffaker, C.B., Kennett, C.E., 1959. A ten-year study of vegetational changes associated with biological control of Klamath weed. J. Range Manage. 12 (2), 69-82.

Hulet, A., Roundy, B.A., Jessop, B., 2010. Crested wheatgrass control and native plant establishment in Utah. Range. Ecol. Manage. 63 (4), 450-460.

Hulme, P.E., 2006. Beyond control: wider implications for the management of biological invasions. J. Appl. Ecol. 43 (5), 835-847.

Jordan, N.R., Larson, D.L., Huerd, S.C., 2008. Soil modification by invasive plants: effects on native and invasive species of mixed-grass prairies. Biol. Invasions. 10 (2), 177-190.

Keane, R.M. and Crawley, M.J., 2002. Exotic plant invasions and the enemy release hypothesis. Trends in Ecol. \& Evol. 17(4), 164-170. 
719 Kettenring, K.M., Adams, C.R., 2011. Lessons learned from invasive plant control experiments:

720

721

722

723

724

725

726

727

728

729

730

731

732

733

734

735

736

737

738

739

a systematic review and meta-analysis. J. Appl. Ecol. 48 (4), 970-979.

Koricheva, J., Gurevitch, J., 2014. Uses and misuses of meta-analysis in plant ecology. J. Ecol. $102(4), 828-844$.

Kuebbing, S.E., Nuñez, M.A., Simberloff, D., 2013. Current mismatch between research and conservation efforts: the need to study co-occurring invasive plant species. J. Biol. Conserv. 160, 121-129.

Kuebbing, S.E., Nuñez, M.A., 2015. Negative, neutral, and positive interactions among nonnative plants: patterns, processes, and management implications. Glob. Chang. Biol. $21(2), 926-934$.

Larson, DL., Larson, J.L., 2010. Control of one invasive plant species allows exotic grasses to become dominant in northern Great Plains grasslands. Biol. Conserv. 143 (8), 19011910.

Laufenberg, S.M., Sheley, R.L., Jacobs, J.S., Borkowski, J., 2005. Herbicide Effects on Density and Biomass of Russian Knapweed (Acroptilon repens) and Associated Plant Species. Weed Technol. 19 (1), 62-72.

Lesica, P., Hanna, D., 2004. Indirect effects of biological control on plant diversity vary across sites in Montana grasslands. Conserv. Biol. 18 (2), 444-454.

Loh, R.K., Daehler, C.C., 2008. Influence of woody invader control methods and seed availability on native and invasive species establishment in a Hawaiian forest. Biol. Invasions $10(6), 805-819$. 
740 Liu H., Stiling P., 2006. Testing the enemy release hypothesis: a review and meta-analysis. Biol. $741 \quad$ Invasions 8(7), 1535-1545.

742 Luken, J.O., 1990. Directing ecological succession. Chapman and Hall, New York, New York, $743 \quad$ USA.

744 MacDougall, A.S., Turkington, R., 2005. Are invasive species the drivers or passengers of $745 \quad$ change in degraded ecosystems? Ecology. $86(1), 42-55$.

746 Mack, R.N., Simberloff, D., Mark Lonsdale, W., Evans, H., Clout, M., Bazzaz, F.A., 2000.

747 Biotic invasions: causes, epidemiology, global consequences, and control. Ecol. Appl. $748 \quad 10(3), 689-710$.

749 Madsen, M.D., Davies, K.W., Mummey, D.L., Svejcar, T.J., 2014. Improving restoration of 750 exotic annual grass-invaded rangelands through activated carbon seed enhancement 751 technologies. Range. Ecol. Manage. 67 (1), 61-67.

752 Madsen, M.D., Davies, K.W., Williams, C.J., Svejcar, T.J., 2012. Agglomerating seeds to 753 enhance native seedling emergence and growth. J. Appl. Ecol. 49(2), 431-438.

754 Magnoli, S.M., Kleinhesselink, A.R., Cushman, J.H., 2013. Responses to invasion and invader 755 removal differ between native and exotic plant groups in a coastal dune. Oecologia. 756 173(4), 1521-1530.

757 Mason, T.J., French, K., 2007. Management regimes for a plant invader differentially impact 758 resident communities. Biol. Conserv. 136(2), 246-259. 
Meiners, S.J., Cadotte, M.W., Fridley, J.D., Pickett, S.T.A., Walker, L.R., 2015. Is successional research nearing its climax? New approaches for understanding dynamic communities. Functional Ecology 29(2), 154-164.

Myers, J.A., Harms, K.E., 2009. Seed arrival, ecological filters, and plant species richness: a meta-analysis. Ecol. Lett. 12 (11), 1250-1260.

Ogden, J.E., Rejmánek, M., 2005. Recovery of native plant communities after the control of a dominant invasive plant species, Foeniculum vulgare: implications for management. Biol. Conserv. 125(4), 427-439.

Olson, B.E., Wallander, R.T., 1998. Effect of sheep grazing on a leafy spurge-infested Idaho fescue community. J. Range Manage. 51(2), 247-252.

Ortega, Y.K., Pearson, D.E., 2010. Effects of picloram application on community dominants vary with initial levels of spotted knapweed (Centaurea stoebe) invasion. Invasive Plant Sci. Manage. 3 (1), 70-80.

Ortega, Y.K., Pearson, D.E., 2011. Long-term effects of weed control with picloram along a gradient of spotted knapweed invasion. Range. Ecol. Manage. 64 (1), 67-77.

Osenberg, C.W., Sarnelle, O., Cooper, S.D., Holt, R.D., 1999. Resolving ecological questions through meta-analysis: goals, metrics, and models. Ecology. 80, 1105-1117.

Pearson, D.E., Icasatti, N.S., Hierro, J.L., Bird, B.J., 2014. Are local filters blind to provenance? Ant seed predation suppresses exotic plants more than natives. PLoS ONE 9 (8), 1-11. 
778 Pearson, D.E., Ortega, Y., 2009. Managing invasive plants in natural areas: moving beyond weed

779

780

781

782

783

784

785

786

787 788

789

790

791

792

793

794

795

796

797 control. Weeds: management, economic impacts and biology. Nova Science Publishers, New York.

Pearson, D.E., Ortega, Y.K., Sears, S.J., 2012. Darwin's naturalization hypothesis up-close: Intermountain grassland invaders differ morphologically and phenologically from native community dominants. Biol. Invasions. 14 (4), 901-913.

Pearson, D.E., Y.K. Ortega, O. Eren, J.L. Hierro, 2015. In press. Quantifying “apparent” impact and distinguishing impact from invasiveness in multispecies plant invasions. Ecol. Appl. 00, 00-00.

Pimentel, D., Zuniga, R., Morrison, D., 2005. Update on the environmental and economic costs associated with alien-invasive species in the United States. Ecol. Econ. 52 (3), 273-288.

Pokorny, M.L., Mangold, J.M., Hafer, J., Denny, M.K., 2010. Managing Spotted Knapweed (Centaurea stoebe)-Infested Rangeland after Wildfire. Invasive Plant Sci.Manage. 3 (2), 182-189.

Pyšek, P., Richardson, D.M., Pergl, J., Jarošík, V., Sixtová, Z. and Weber, E., 2008. Geographical and taxonomic biases in invasion ecology. Trends in Ecology \& Evolution 23(5), 237-244.

Reid, A.M., Morin, L., Downey, P.O., French, K., Virtue, J.G., 2009. Does invasive plant management aid the restoration of natural ecosystems?. Biol. Conserv. 142 (10), 23422349. 
Ricciardi, A., Rasmussen, J.B., 1998. Predicting the identity and impact of future biological invaders: a priority for aquatic resource management. Can. J. Fish. Aq. Sci. 55 (7), 17591765.

Rinella, M.J., Maxwell, B.D., Fay, P.K., Weaver, T., Sheley, R.L., 2009. Control effort exacerbates invasive-species problem. J. Ecol. Appl. 19 (1), 155-162.

Rosenberg, M.S., 2005. The file-drawer problem revisited: a general weighted method for calculating fail-safe numbers in meta-analysis. Evolution 59 (2), 464-468.

Rosenberg, M.S., Adams, D.C., Gurevitch, J., 2000. MetaWin: Statistical Software for MetaAnalysis. Version 2.0. Sinauer Associates, Massachusetts.

Ruwanza, S., Gaertner, M., Esler, K.J., Richardson, D.M., 2013. Both complete clearing and thinning of invasive trees lead to short-term recovery of native riparian vegetation in the Western Cape, South Africa. Appl. Veg. Sci. 16 (2), 193-204.

Saito, T.I., Tsuyuzaki, S., 2012. Response of riparian vegetation to the removal of the invasive forb, Solidago gigantea, and its litter layer. Weed Biol. Manage. 12 (2), 63-70.

Seabloom, E.W., Borer, E.T., Boucher, V.L., Burton, R.S., Cottingham, K.L., Goldwasser, L., Gram, W.K., Kendall, B.E., Micheli, F., 2003. Competition, seed limitation, disturbance, and reestablishment of California native annual forbs. Ecol. Appl. 13, 575-592.

Schwartz, M.W., Hoeksema, J.D., Gehring, C.A., Johnson, N.C., Klironomos, J.N., Abbott, L.K., Pringle, A., 2006. The promise and the potential consequences of the global transport of mycorrhizal fungal inoculum. Ecol. Lett. 9 (5), 501-515. 
818 Skurski, T.C., Maxwell, B.D., Rew, L.J., 2013. Ecological tradeoffs in non-native plant management. Biol. Conserv. 159, 292-302.

820 Sheley, R.L., Mangold, J.M., Anderson, J.L., 2006. Potential for successional theory to guide 821 restoration of invasive-plant-dominated rangeland. Ecol. Monogr. 76 (3), 365-379.

822 Sher, A.A., Gieck, S., Brown, C.S., Nissen, S.J., 2008. First-Year Responses of Cheatgrass

823 Following Tamarix spp. Control and Restoration-Related Disturbances. Rest. Ecol. 16

824 (1), 129-135.

825

Sinden, J., Jones, R., Hester, S., Odom, D., Kalisch, D., James, R., Cacho, O., Griffith, G., 2005. 826 The economic impact of weeds in Australia. Plant Prot. Q. 20, 25-32.

827 Smith, R.F., Van der Bosch, R., 1967. Integrated control. Academic Press, NY.

828 Stanley, A.G., Kaye, T.N., Dunwiddie, P.W., 2011. Multiple treatment combinations and seed 829 addition increase abundance and diversity of native plants in Pacific Northwest prairies. Ecol. Restor, 29 (1-2), 35-44.

831 Stewart, G., 2010. Meta-analysis in applied ecology. Biol. Lett. 6 (1), 78-81.

832 Symstad, A.J., 2004. Secondary invasion following the reduction of Coronilla varia 833 (crownvetch) in sand prairie. Am. Midl. Nat. 152 (1), 183-189.

834 Tyser, R.W., Asebrook, J.M., Potter, R.W., Kurth, L.L., 1998. Roadside revegetation in Glacier 835 National Park, USA: effects of herbicide and seeding treatments. Restor. Ecol. 6 (2), 197836 206. 
837 Vitousek, P.M., Aber, J.D., Howarth, R.W., Likens, G.E., Matson, P.A., Schindler, D.W.,

838

839

840

841

842

843

844 Yelenik, S.G., Stock, W.D., Richardson, D.M., 2004. Ecosystem level impacts of invasive

845

846

847

848

Schlesinger, W.H., Tilman, D.G., 1997. Human alteration of the global nitrogen cycle: sources and consequences. J. Ecol. Appl. 7 (3), 737-750.

Wilson, R.G., Boelk, D., Kyser, G.B., DiTomaso, J.M., 2008. Integrated management of perennial pepperweed (Lepidium latifolium). Invasive Plant Sci. Manage. 1 (1), 17-25.

Wolf, F.M., J.P. Guevara., 2001. Imputation of missing data in systematic reviews: So what is the standard deviation? Cochrane 1, 7. Acacia saligna in the South African fynbos. Restor. Ecol. 12 (1), 44-51.

Zavaleta, E.S., Hobbs, R.J., Mooney, H.A., 2001. Viewing invasive species removal in a wholeecosystem context. Trends Ecol. Evol. 16 (8), 454-459. 
849 Table 1. Results of meta-analysis comparing effects of invasive plant control treatments among

850 three target invader types: grasses, forbs, and woody species. Summary statistics including mean

851 effect sizes (Hedges $d_{+}$) are given for three response variables representing the abundance of

852 target invaders, secondary invaders, and native plants, respectively. Negative mean effect sizes

853 indicate that treated plots had on average lower abundance of the response variable, while

854 positive effect sizes indicate higher abundance. A mean effect size significantly differs from

855 zero when its $95 \%$ confidence interval does not bracket zero.

856

\begin{tabular}{|c|c|c|c|c|c|c|c|c|c|}
\hline \multirow{2}{*}{$\begin{array}{l}\text { Target } \\
\text { type }\end{array}$} & \multicolumn{3}{|c|}{ Target effect } & \multicolumn{3}{|c|}{ Secondary effect } & \multicolumn{3}{|c|}{ Native effect } \\
\hline & $n$ & $d_{+}$ & $95 \% \mathrm{CI}$ & $n$ & $d_{+}$ & $95 \% \mathrm{CI}$ & $n$ & $d_{+}$ & $95 \% \mathrm{CI}$ \\
\hline Grass & 20 & -1.34 & -1.88 to -0.85 & 20 & 0.46 & 0.17 to 0.72 & 12 & 0.22 & -0.13 to 0.58 \\
\hline Forb & 28 & -1.93 & -2.60 to -1.41 & 29 & 0.67 & 0.38 to 0.99 & 14 & 0.13 & -0.25 to 0.45 \\
\hline Woody & 4 & -1.41 & -3.72 to -0.41 & 11 & 0.52 & -0.22 to 1.29 & 5 & 0.72 & 0.0006 to 1.68 \\
\hline
\end{tabular}

857

858

859 


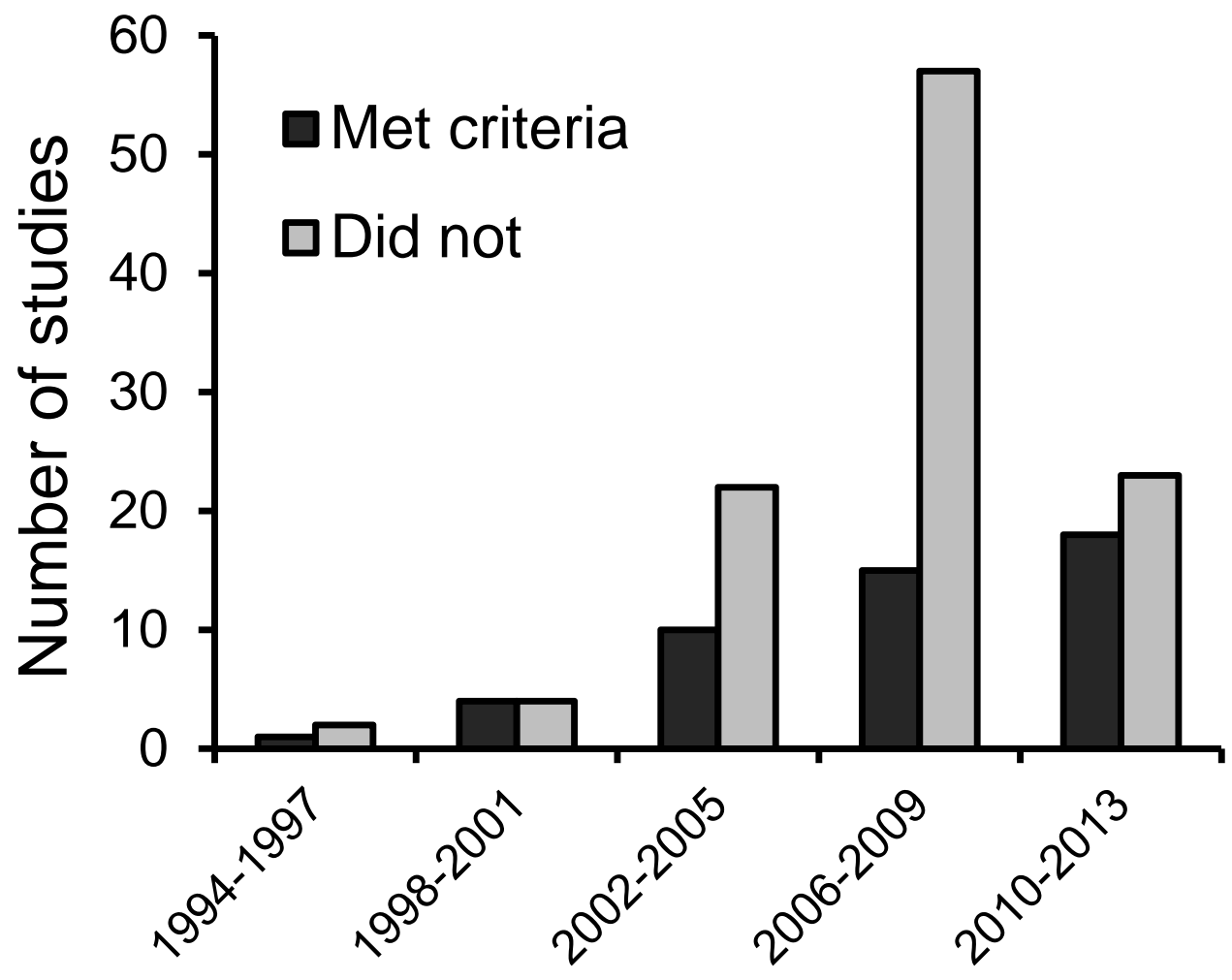

866

867 Fig. 1. Number of studies meeting vs not meeting criteria for evaluation of secondary invasion in 868 a global review of invasive plant management research. Data not shown for studies published 869 before $1994(n=11)$ or after $2013(n=1)$. 
a) Target invader

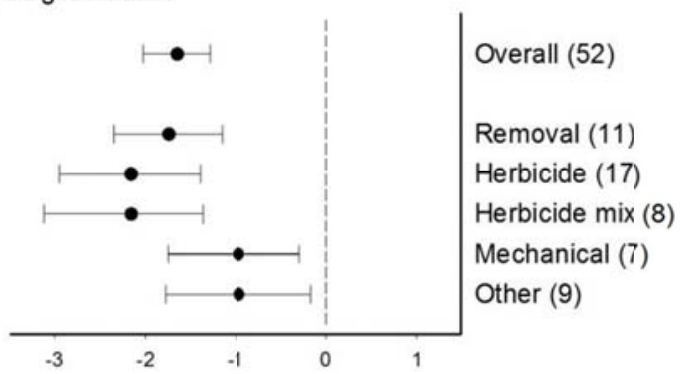

b) Secondary invader

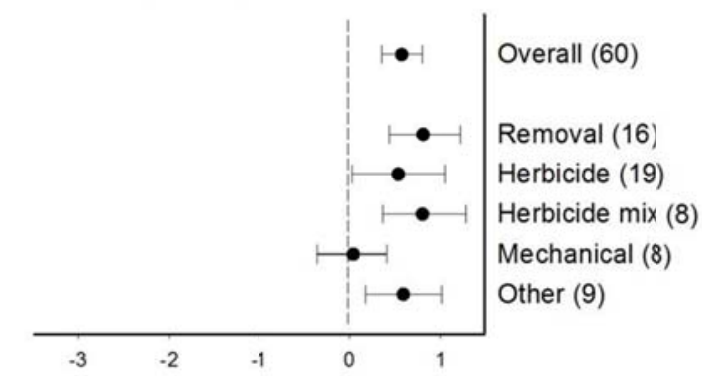

C) Natives

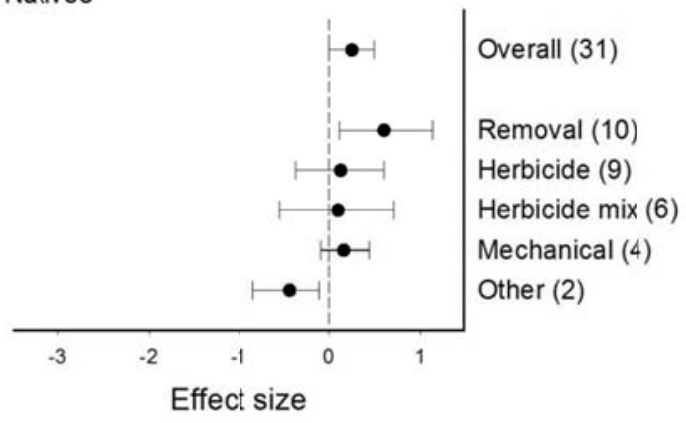

870

871 Fig. 2. Results of a meta-analysis quantifying effects of invasive plant control treatments on a)

872 abundance of target invaders, b) secondary invaders, and c) native plants. Mean effect sizes

873 (Hedges $d_{+}$) were calculated across all cases ('overall') and for differing treatment methods (see

874 Methods). Mean effect sizes significantly differ from zero when their $95 \%$ confidence intervals

875 (denoted by bars), do not bracket zero; negative values indicate lower abundance in treated plots,

876 while positive values indicate higher abundance. 
a)

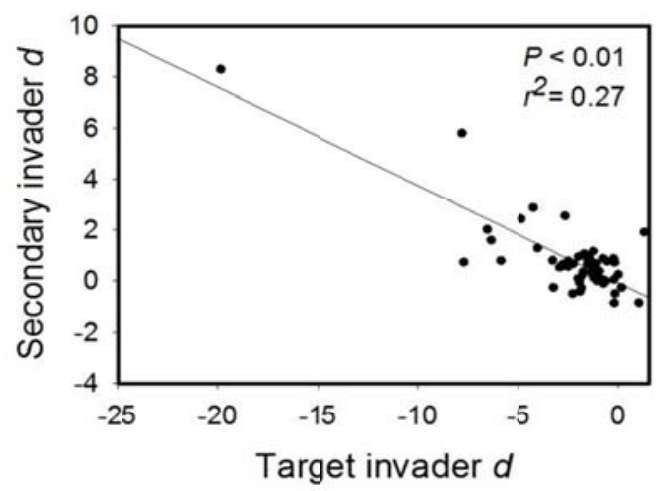

b)

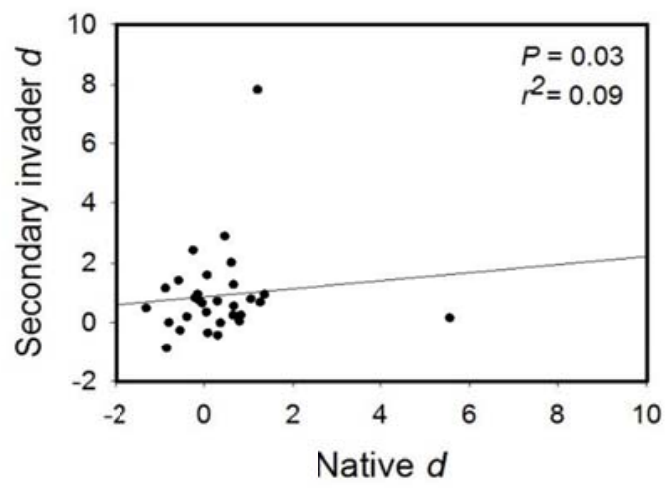

c)

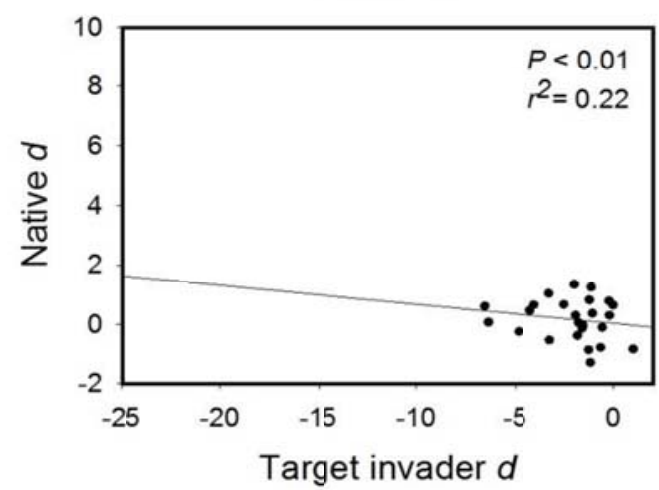

878 Fig. 3. Results of a meta-regression relating effects of invasive plant control treatments on

879 abundance of target invaders, secondary invaders, and native plants. Each point represents one

880 case study and the corresponding effect sizes (Hedges $d$ ) calculated for: a) secondary vs target

881 invaders, b) secondary invaders vs natives, and c) natives vs target invaders. Negative effect

882 sizes indicate lower abundance in treated plots, while positive values indicate higher abundance. 


\section{Considerations for averting secondary invasion}

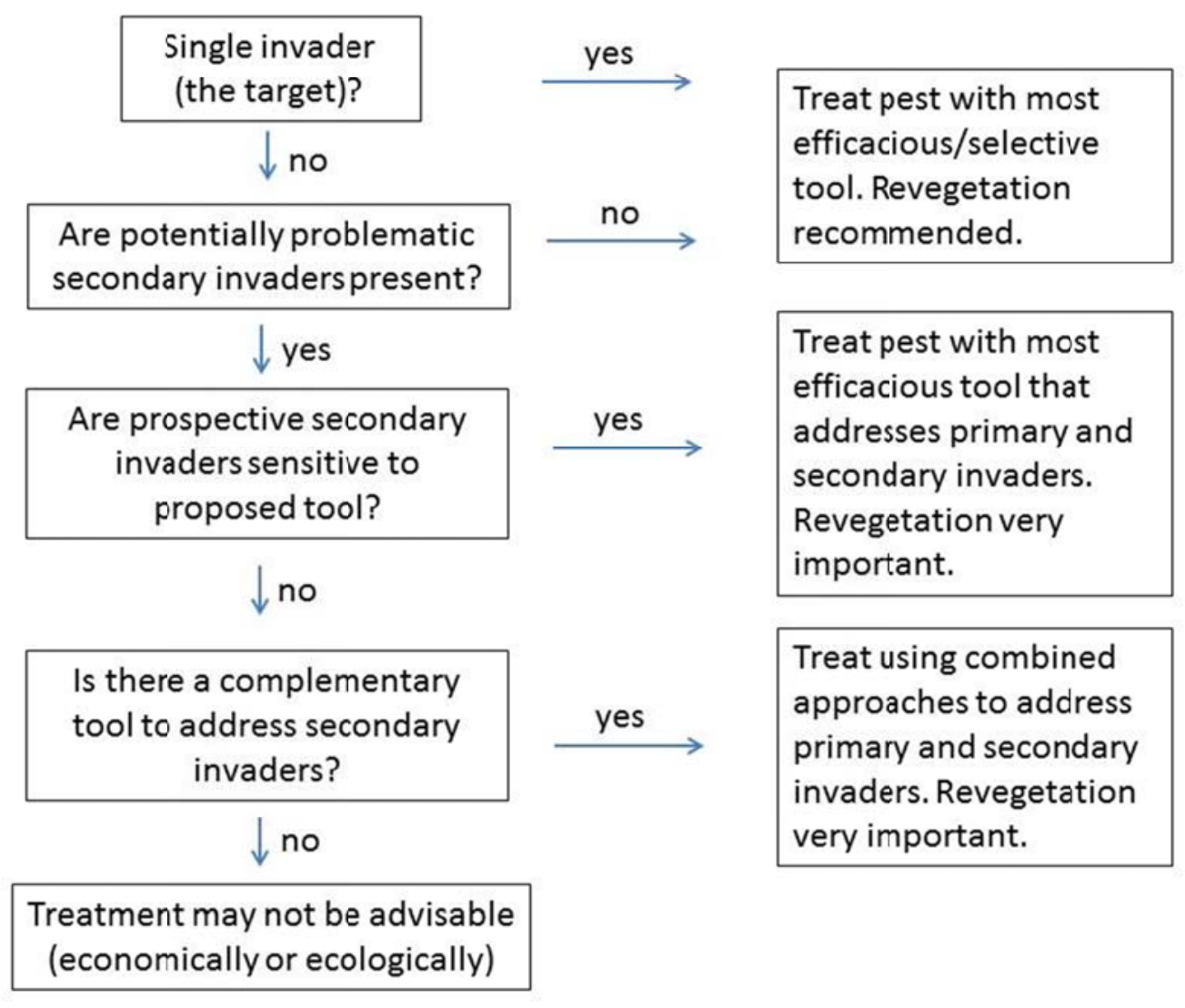

887

888 Fig. 4. Dichotomous guide to management actions for reducing the risk and severity of

889 secondary invasion based on current rudimentary understandings from our meta-analysis and

890 literature review.

891 